\title{
Physiotherapy student experience of a mindful movement and a mindful stress-reduction intervention: A qualitative study
}

Janet McConville BAppSci (Physio), GradCertHE, MSportsPhysio

Senior Lecturer, Discipline of Physiotherapy, Latrobe University, Victoria, Australia

Deborah Lewis Dip Ed, MPsych (Counselling)

Richard Chambers DPsych (Clinical), MAPS

Campus Community Division, Monash University, Victoria, Australia

Craig Hassed MBBS, FRACGP, OAM

Associate Professor, Department of General Practice, Monash University, Victoria, Australia

\section{ABSTRACT}

Increasing levels of psychological distress in university student populations are a growing concern. Mindfulness training provides a potential intervention to improve well-being outcomes. This paper uses a thematic analysis approach to explore the experiences of pre-clinic physiotherapy students participating in a six-week mindfulness programme based on either sitting meditation or mindful movement. Semi-structured interviews were conducted with 12 students immediately post-intervention and six students at a six-week follow-up. Interviews were transcribed and coded, and the data analysed and interpreted. One main theme (increased self-awareness) and five sub-themes (mental health, self-care, communication, study engagement, and awareness of movement) were identified. Participants were more aware of their own stress response and the mental processes, such as rumination, that gave rise to these experiences. Participants reported making healthier lifestyle choices, including increased exercise and improved diet. They reported improved listening and communication, and study time was more focused and productive. Participants in the mindful movement group also reported increased awareness of their own physical movement and that of others. Participants engaged well with both the six-week mindful stress-reduction intervention and six-week mindful movement intervention, reporting improvements in well-being, communication and academic engagement.

McConville, J., Lewis, D., Chambers, R., \& Hassed, C. (2019). Physiotherapy student experience of a mindful movement and a mindful stress-reduction intervention: A qualitative study. New Zealand Journal of Physiotherapy, 47(3), $172-182$. https://doi.org/10.15619/NZJP/47.3.05

Key Words: Mindful Movement, Mindfulness, Physiotherapy Student, Stress, Study Engagement, Qualitative

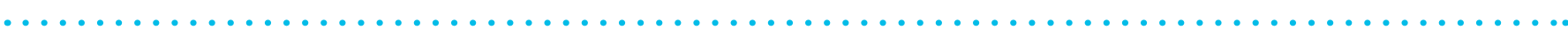

\section{INTRODUCTION}

University students report higher levels of psychological distress across diverse areas of study compared to the general population (Larcombe, Finch, \& Sore, 2015). The academic and clinical requirements of health professional training in particular can lead to increased levels of stress, poor mental health and unhealthy lifestyle behaviours in students (Dyrbye, Thomas, \& Shanafelt, 2006). Persistent stress may lead to high allostatic load with adverse effects on physical health and atrophy of neurons in brain regions, important for learning, memory and executive functioning (McEwen, 2004). Strategies that equip students to manage psychological distress will, therefore, be a valuable addition to any professional training programme since they may enhance student well-being and learning. There is also some evidence that mindfulness training for healthcare professionals (HCPs) not only enhances well-being but also leads to better patient care in terms of greater empathy and improved communication (Epstein, Siegel, \& Silberman, 2008; Fahrenkopf et al., 2008).

Mindfulness training is one approach which has been utilised to decrease stress and anxiety for students in health profession programmes (Slonim, Kienhuis, Di Benedetto, \& Reece, 2015).
A recent meta-analysis of 38 studies on the effectiveness of mindfulness-based interventions for distress, well-being, physical health, and performance in HCPs and HCPs-in-training showed that these interventions had a significant moderate effect on anxiety, depression, psychological distress, and stress, and small to moderate effects were found for burnout and well-being at post-intervention. Larger intervention effects were observed with mindfulness-based stress reduction (Spinelli, Wisener, \& Khoury, 2019).

It is beyond the scope of this paper to discuss the definition and operationalisation of mindfulness in detail, but briefly, the most widely used definition of mindfulness is "the awareness that emerges through paying attention on purpose, in the present moment, and non-judgmentally to the unfolding experience moment by moment" (Kabat-Zinn, 2003, p.145). Mindfulness as a term, however, can refer to many different things. For example, it can be seen as a trait in terms of being an everyday experience, in that we all have moments throughout the day where we are fully present and engaged with the task at hand. Mindfulness can also be described as a state in terms of being mindful or unmindful in a given moment in time. Mindfulness can also be seen as a practice where a person intentionally cultivates state or trait mindfulness through formal (meditation) 
and informal practices (daily life) (Grossman, Niemann, Schmidt, \& Walach, 2004; Shapiro, Carlson, Astin, \& Freedman, 2006).

Mindfulness-based interventions such as mindfulness-based stress reduction (Kabat-Zinn, 2003) and mindfulness-based cognitive therapy (Segal, Williams, \& Teasdale, 2002) have proven effective in increasing mindfulness, self-efficacy and empathy, and decreasing stress, anxiety, and depression in groups of medical, psychology, nursing, and other health profession students (McConville, McAleer, \& Hahne, 2017). Qualitative studies with psychology (Hopkins \& Proeve, 2013), occupational therapy (Stew, 2011), and nursing (van der Riet, Rossiter, Kirby, Dluzewska, \& Harmon, 2015) students report better ability to cope with stress, improved self-awareness and better patient/client care following such programmes.

Mindfulness-based interventions generally include formal meditation practices like body scan and breath meditation, and informal practices and applications where participants are taught how to use mindfulness practice during everyday activities or for specific challenges, such as study or stress reduction. These sitting, formal practices of mindfulness commonly use the body and senses as an anchor for the present moment, and, as a result, lead to increased bodily awareness and interoception, which are very helpful for various psychological disorders (Price, Merrill, McCarty, Pike, \& Tsui, 2019; Khoury, Lutz, \& Schuman-Olivier). Some interventions include mindful movement practices, for example, the mindful yoga component of mindfulness-based stress reduction. There is a growing interest in the use of mindful movement (MMov) to increase awareness of mental reactions, mental states and body awareness, and decrease stress and anxiety (Kinser, Braun, Deeb, Carrico \&Dow, 2016). MMov cultivates a present-moment focused state of mind and attention by paying attention to body sensations, proprioception, and breathing, and some people, particularly those with anxiety and attentional problems, may find body-oriented therapies and MMov much easier to practise than sitting meditation (Price \& Hooven 2018). MMov includes traditional forms like Tai Chi, yoga and Qigong, but other potential forms of MMov are the Feldenkrais Method, Alexander Technique, and dance. The Feldenkrais Method, also known as Awareness Through Movement, has been found to decrease state anxiety in physiotherapy students (Kolt \& McConville, 2000). However, a review of the outcomes of MMov on reducing stress and anxiety was unable to draw definitive conclusions (Payne \& Crane-Godreau, 2015). Qualitative studies indicate a possible benefit of MMov. Medical students participating in a yoga programme reported an improved ability to cope with stress, perceived reconnection of mind and body, and confidence with using mind-body skills with patients (Bond et al., 2013).

Given the limited research into MMov interventions, there is a need for further research in this area. One potential barrier to implementing MMov as core curriculum, rather than an elective programme, could be the perceived cultural barriers of practices like yoga, Qigong and Tai Chi. Just as interventions such as mindfulness-based stress reduction and mindfulnessbased cognitive therapy secularise mindfulness (that is, decontextualise it from its Buddhist/spiritual roots), it is vital to similarly decontextualise MMov and assess the effectiveness and acceptability of these programmes by health science students, who are more likely to accept interventions that are both secular and scientific.

We are not aware of any studies that have specifically investigated mindfulness-based interventions for physiotherapy students. Lo, Francis-Cracknel, and Hassed (2017) evaluated a mindfulness-based lifestyle programme (Health Enhancement Program) for physiotherapy students at Monash University, where mindfulness has been incorporated as part of the core curriculum. However, due to the multiple elements, it is not possible to determine the relative contributions of the mindfulness and lifestyle components to the outcomes of this programme. Interestingly, participants reported enjoying the mindfulness activities and adoption of healthier lifestyle behaviours. While stress was found to increase in this cohort, this could be explained by a variety of factors. For example, it could be a reflection of the fact that the post-course measures were taken during a major assessment period or the increased reporting of stress was a sign of growing interoception with the intervention not continuing for long enough to help students go to the next stage of being able to minimise stress. There was also no control group. A study of Monash medical students receiving a more extensive form of the Health Enhancement Program found pre-post improvements in mental health despite the post-course evaluation taking place during the high-stress assessment pre-exam period (Hassed, de Lisle, Sullivan, \& Pier, 2009). Providing different options for learning mindfulness may improve engagement and make the programmes more relevant and adaptable to specific tertiary education contexts (Dobkin \& Hassed, 2016). MMov may be particularly useful for physiotherapy students with their assumed natural proclivity for exercise and physical interventions.

To address some of the issues highlighted above, in this study we developed two mindfulness interventions tailored to address the specific challenges faced by physiotherapy students, designed to be compatible with their science education and resonate with their interest in physical movement. The aim of the study was to explore the lived experience of third-year physiotherapy students who participated in a six-week mindful stress-reduction (MSR) intervention or MMov intervention during their pre-clinic semester.

\section{METHODS}

A qualitative analytic method using semi-structured interviews was employed. The aim was to identify themes that richly described the lived experience of the students during these programmes.

\section{Design}

The thematic analysis method described by Braun and Clarke (2006) was used to identify, analyse and report patterns of meaning (themes) within the data set. Themes were induced from the data rather than being analysed using a pre-existing theoretical framework. In doing this, reference to the concept of the theme was sought across all participants. The explicit meaning of the data was used to identify and describe themes, as it was assumed that the participants' descriptions accurately described their experience and reality (Braun \& Clarke, 2006). Ethical approval was obtained from the Human Research Ethics 
Committee of La Trobe University (reference FHEC 1413). All participants gave written informed consent.

\section{Participants}

A cohort of 123 third-year pre-clinic physiotherapy students attended a two-hour core curricular Introduction to Mindfulness lecture, which included instruction on how to apply mindfulness practice in personal and professional settings. Following a subsequent invitation, 17 students agreed to participate in this research and were randomly allocated to either an MSR or MMov group. Both groups participated in six one-hour sessions, timetabled over the first six weeks of the 12-week semester.

\section{Interventions}

Mindful stress reduction (MSR)

The MSR intervention consisted of six one-hour weekly sessions. Each session introduced a different application of mindfulness and associated sitting meditation and informal practices, mainly focused around stress reduction. Participants were encouraged to practice these meditations and apply the informal practices in their everyday lives. Time was devoted in each session to discussing insights gained and challenges faced in attempting and achieving meditations and informal practices.

\section{Mindful movement (MMov)}

The MMov intervention also consisted of six one-hour weekly sessions. Each session covered the same basic topic/application as the MSR intervention, although the meditations and informal practices were based on mindful movement. Again, participants were encouraged to practise the mindful movement exercises each day and were coached in applying mindful movement to their everyday life, with a focus on reducing stress. Both interventions were led by a clinical psychologist and experienced mindfulness facilitator, who was also one of the researchers $(\mathrm{RC})$.

The focus of each session and the weekly homework practices are summarised in Table 1.

Data collection

Interviews were conducted following the completion of the programme (week six or seven of the semester) and at a sixweek follow-up (pre-exam, end-of-semester). Audio recorded interviews were conducted on campus and lasted for an average length of 46 minutes. Experience of mindfulness was investigated post-intervention by asking questions in relation to the effect of mindfulness on aspects of life, awareness of attention, awareness of thoughts, relationship to self, and relevance of mindfulness to the trainee physiotherapists. At the six-week follow-up, questions covered the topics of becoming mindful, the perceived benefits of mindfulness, and factors helping or hindering practice as well as individual follow-up. An opening statement introduced the participant to each topic area. This was followed by a question, and then further questioning if required. The schedule was flexible, enabling the students to talk about, reflect on, and learn from their own unique experience.

All interviews were conducted by a student enrolled in an Honours degree psychology programme who was not involved in the mindfulness programme or in student teaching (GE). (See Appendix A for post-intervention interview and follow-up questions).

Table 1: Focus of each session and weekly at-home practices

\begin{tabular}{|c|c|c|}
\hline Week & Mindful stress reduction & Mindful movement \\
\hline 1 & $\begin{array}{l}\text { Introducing mindfulness } \\
\text { Body scan } 5 \text { min twice a day } \\
\text { Notice how much (1) paying attention and (2) in "default } \\
\text { mode" (distracted/daydreaming) and effect of each }\end{array}$ & $\begin{array}{l}\text { Introducing mindfulness } \\
\text { Body scan } 5 \text { min twice a day } \\
\text { Notice how much (1) paying attention and (2) in "default } \\
\text { mode" (distracted/daydreaming) and effect of each }\end{array}$ \\
\hline 2 & $\begin{array}{l}\text { Reducing stress } \\
\text { Breath meditation } 5 \text { min twice a day } \\
\text { Noticing when fight/flight (stress) response triggered and } \\
\text { using mindfulness to disconnect from it }\end{array}$ & $\begin{array}{l}\text { Releasing tension } \\
\text { Tensing and relaxing } 5 \text { min twice a day } \\
\text { Noticing and releasing physical / mental tension throughout } \\
\text { day }\end{array}$ \\
\hline 3 & $\begin{array}{l}\text { Compassion } \\
\text { Mindful listening meditation } 10 \text { min twice a day } \\
\text { Recognising self-criticism and practising self-compassion }\end{array}$ & $\begin{array}{l}\text { Moving mindfully } \\
\text { Mindful walking } 10 \text { min twice a day } \\
\text { Moving/commuting mindfully }\end{array}$ \\
\hline 4 & $\begin{array}{l}\text { Acceptance/letting go } \\
\text { Mindfulness of thoughts } 10 \text { min twice a day } \\
\text { Noticing conflict/tension and letting go }\end{array}$ & $\begin{array}{l}\text { Efficient/compassionate movement } \\
\text { Compassionate body scan/mindful yoga } 10 \text { min twice a day } \\
\text { Using minimal effort throughout daily activities }\end{array}$ \\
\hline 5 & $\begin{array}{l}\text { Improving productivity } \\
\text { Choiceless awareness } 15 \text { min twice a day } \\
\text { Unitasking (instead of multitasking) }\end{array}$ & $\begin{array}{l}\text { Joyful movement } \\
\text { Free movement / dance } 15 \text { min twice a day } \\
\text { Awareness of joyful movement throughout day }\end{array}$ \\
\hline 6 & Course review and maintaining the practice & Course review and maintaining the practice \\
\hline
\end{tabular}




\section{Data analysis}

All students were assigned an ID number, and audio recordings were de-identified. All interviews were transcribed verbatim by one of the researchers (DL). Transcripts were checked against the audio recordings for accuracy.

Two researchers ( $D L$ and JM) independently analysed the data. All transcripts were first read in their entirety to get an overall sense of the students' experience. The transcripts were then read line by line and codes were assigned in a systematic way across the data set. These codes were then collated into themes. The two researchers then came together, and through consensus and discussion, formulated final themes, further refining these through checking that they were consistent with the codes and data set. Data analysis was therefore an iterative process that involved multiple readings of the transcripts. Extracts from the data set were then selected. Themes were analysed in relation to the research topic and the literature (Braun \& Clarke, 2006).

\section{RESULTS}

Of the 17 students who participated in the research, 12 agreed to be interviewed. Twelve were interviewed at the completion of the programme (five from MSR and seven from MMov). Due to attrition, only six students completed follow-up interviews (four MSR and two MMov). The mean age of the participants was 24.7 years, with an even distribution of women and men. The median number of sessions attended was 5.5. There was low attendance at the six-week follow-up, as the interviews were conducted in the week prior to end-of-semester exams, and students reported they could not afford the time. Participant characteristics are presented in Table 2.
A total of 18 interviews were analysed. The six-week and12week individual interviews from the MSR and MMov groups were analysed as one data set as the researchers sought to understand the lived experience following participation in a mindfulness-based intervention. Each participant had a different narrative about the effect of mindfulness training in their life. However, four themes were identified as being common across the participants. An additional theme of movement awareness was identified across participants in the MMov group. Information relating to "barriers to practice" from the week-12 interviews has also been included.

\section{Main theme}

The main theme from both groups was increased self-awareness (i.e. being more aware of their physical, mental and emotional states). This is the meta skill which makes all the other abilities possible.

\section{Sulb-themes}

The five sub-themes identified were: (1) mental health, (2) self-care, (3) communication, (4) study engagement and (5) movement awareness. Subthemes with supporting quotes are described below, with additional supporting quotes in Appendix B.

\section{Mental health}

Semester one for third year students is a "high-stakes" semester, with potential for high levels of stress. Participants reported recognising the stress response in themselves - such as increased muscle tension and heart rate - enabling them to use strategies from the training to decrease the physical symptoms and feelings of stress and anxiety:

\section{Table 2: Participant characteristics}

\begin{tabular}{|c|c|c|c|c|}
\hline Participant number & Sex & Age & Group allocation & Number of sessions attended \\
\hline 1 & $\mathrm{~F}$ & 22 & MMov & 5 \\
\hline 2 & $\mathrm{~F}$ & 20 & MMov & 5 \\
\hline $3^{a}$ & $\mathrm{~F}$ & 26 & MMov & 6 \\
\hline $4^{a}$ & M & 27 & MSR & 6 \\
\hline $5^{a}$ & M & 40 & MSR & 6 \\
\hline $6^{a}$ & $\mathrm{~F}$ & 23 & MMov & 5 \\
\hline $7^{a}$ & $\mathrm{~F}$ & 28 & MSR & 6 \\
\hline 8 & $\mathrm{~F}$ & 21 & MMov & 4 \\
\hline 9 & M & 20 & MMov & 4 \\
\hline $10^{a}$ & M & 20 & MSR & 5 \\
\hline 11 & M & 25 & MSR & 6 \\
\hline 12 & M & 25 & MMov & 6 \\
\hline
\end{tabular}

Note: F, female; M, male; MMov, mindful movement, MSR, mindful stress reduction

a Participant attended both interviews 
Over the last few weeks with assessments... I can really feel my heart rate increasing... I didn't sit there and panic, as I maybe used to, I was able to recognise there were physiological signs of stress and take action. (Participant 3)

There appeared to be an awareness of rumination, self-created perceptions of threat, excessive thinking, excessive judgement, catastrophising and reactivity. Through increased self-awareness, students shifted into a less stressed, more accepting space of presence, including self-acceptance, acknowledgement and kindness: "A lot of things that I'm stressed about, it is just me making them bigger than they are. ... I want everything to be perfect and to the highest possible standard, but the pressure is only coming from me" (Participant 2); "I haven't got as down on myself. I have tried to focus myself back into the moment, so I haven't had as many bad thoughts like "you're going to fail this, you're not going to do well" (Participant 8).

\section{Self-care}

Participants reported bringing increased attention and kindness to self when engaging in everyday activities, improving the experience of these activities. Participants reported prioritising exercise and making better food choices: "Leisure time has become actual guilt-free leisure time...I've accepted that me getting up and exercising for half an hour isn't a waste of time" (Participant 3); "Every meal, everything I eat, I slow down, kind of enjoy it more, and I guess I eat less of what I know I shouldn't eat" (Participant 11).

Participants reported improved sleep linking this to a variety of practices, including meditation, progressive muscle relaxation, body scan, mindful movement and dancing: "Now if I do a 10to 15-minute mindful movement activity, I fall asleep so much quicker than I used to, which is having a huge effect on my general well-being" (Participant 6).

\section{Communication}

When communicating with others, participants reported being more aware of when they were trying to multitask or when their attention wandered. In noticing their attention wandering, they were able to bring it back to the other person: "I noticed that when I listen to someone, I kind of lose my concentration ... This programme has helped me to be aware of myself, then bring myself back to the current situation and what is being said" (Participant 4); "I've stopped multitasking and texting and stuff when I speak to people...not being distracted while speaking to them [people] helps [me] to communicate better" (Participant 11).

A reported implication was more holistic and effective patient interaction: "[Being] more present in the moment and listening to what they [the patients] are saying, you are actually going to understand more about them, then you are going to give them a better treatment" (Participant 2).

\section{Study engagement}

Participants engaged more in their learning by bringing mindful awareness to academic activities. One of the consistent experiences reported was an increased ability to recognise default mode (where the attention has wandered) and the ability to bring attention back to the task at hand: "When I go to lectures, rather than get halfway through a lecture and realise
I haven't heard any of the previous part, I pick up a lot quicker [when I'm not tuned in] and I can kind of refocus" (Participant 7).

This led to more effective use of time and a reported increase in productivity: "I used to sit down for four or five hours and probably achieve the same as now, if I give myself two hours and be really mindful, not be as much in default mode" (Participant 2).

Participants reported being more accepting of themselves and less reactive, enabling them to stay focused on a task: "When I reflect on what I've done wrong, I take a gentler tone, and it's easier to stay focused, and not just be kind of down on yourself; making mistakes is more productive" (Participant 11).

Participant 5 noted:

... When writing a difficult essay and you're grappling with a concept or how to describe something, often that can induce a stress reaction, and it's an uncomfortable feeling to sit with ... I guess using mindfulness ... I have been able to sit with that difficult feeling a bit longer.

\section{Movement awareness}

All participants in the MMov group reported increased movement awareness, including the few participants who felt personally challenged by some of the activities, specifically the free-dance session. The extent of this awareness was not apparent in the MSR group.

Participants reported the increased awareness of movement in themselves led to a better appreciation of movement in others: "The better you understand your body, the better you're going to be able to understand someone else's body" (Participant 2).

Participants reconceptualised movement re-education for their future patients: "When you're trying to teach a patient a movement ... being able to help them to create a better mindfulness of their body and their movements ... will then allow them to learn new movements a lot better" (Participant 6).

Participants reported that the mindful movement facilitated awareness of the body and the potential to change: "With the mindful movement activities, [it] was a lot easier to identify where I was holding tension in my body, and then by acknowledging that, being able to find a way to rid myself of that" (Participant 6); "I've been feeling my posture a lot more and able to correct it" (Participant 9).

Negative experiences and challenges

Participants identified barriers to formal mindfulness practice. These included lethargy, inconsistent routines, and a perceived lack of time to practise.

During the six weeks of the programme, participants informally applied mindfulness practice in their daily lives. They were motivated by peer support, the face-to-face contact with the facilitator, and weekly follow-up emails with MP3 files of mindfulness practices. However, once the programme finished, the majority did not maintain their practice at the same level. Ongoing mindfulness support is likely to be required for these participants to implement their newly gained mindfulness practice on an ongoing basis during their university studies and 
in the clinical context as healthcare students and professionals: "I was much more vigilant [with practice] when I had a weekly commitment" (Participant 6).

On an individual basis, participants found some practices more useful than others. A feeling of benefit did not necessarily predict practise of the technique: "I didn't find dance useful. I like being told what to do - structure - I am not creative. I am uncoordinated. I liked the walking, tense-relax, and body scan, but I still only practised once or twice a week" (Participant 8).

\section{DISCUSSION}

This study explored the lived experience of physiotherapy students participating in a mindfulness intervention consisting of a two-hour lecture outlining the science of mindfulness, and then either a six-week programme based on sitting meditation (MSR) or mindful movement (MMov). Participants in both programmes reported increased self-awareness and improvement in mental health, self-care, communication and study engagement. The MMov programme participants also reported applying the experiential learning from the movement awareness activities into their practice as trainee physiotherapists.

Participants in both programmes reported greater physical self-awareness through explicitly focusing on body awareness. Noticing signs of the fight/flight/freeze (stress) response, such as muscle tension and increased heart rate, allowed participants to recognise the onset of this response earlier, resulting in lower overall levels of tension.

Being mindfully aware of the stress response - that is, without judgement - also meant that they may have been less caught up in secondary reactions, such as anxiety and panic. This reduced reactivity is a characteristic element of mindfulness-based interventions. As they became more aware of the physiological correlates of the stress response, participants in both the MSR and MMov programmes also reported being able to recognise the triggers and mental processes that gave rise to their experience of stress, such as perfectionism and catastrophising. This is important for a student in a high-pressure programme like physiotherapy, as it results in the locus of control for stress transitioning from external to internal, providing them with an effective strategy to reduce perfectionism, and concomitant stress and anxiety.

Such metacognition and meta-emotion, and concomitantly reduced reactivity are central parts of mindfulness-based interventions. The observed decrease in reactivity would, therefore, be expected as both programmes focused on recognising the stress response and using mindfulness to reduce it. However, as the intervention in the MMov programme primarily focused on developing body awareness, in contrast to the explicit focus on mental processes in the MSR programme, the increased metacognition and decreased perfectionism reported by participants in the MMov group are noteworthy since these appear to have emerged spontaneously from the training. This is consistent with the findings of Chrisman, Christopher, and Lichtenstein (2009), who reported that students participating in mindful movement practices experienced emotional, physical and mental changes. This finding also concurs with research showing that increased physical self-awareness (awareness of bodily sensations and the reciprocal relationship these sensations have with emotion) may be a key mechanism in mindfulness-based interventions such as mindfulness-based cognitive therapy (Michalak, Burg, \& Heidenreich, 2012). This non-judgemental attitude may also have arisen through modelling by the course facilitator - a recognised key aspect of successful mindfulness teaching (Segal et al., 2002).

In this study, increased mindful awareness appeared to be associated with healthier choices, such as regular exercise and improved diet and sleep. This concurs with previous research that has shown mindfulness meditation only (Black, O'Reilly, Olmstead, Breen, \& Irwin, 2015), mindful movement (Caldwell, Harrison, Adams, Quin, \& Greeson, 2010), and mindfulnessbased stress reduction are all associated with improved sleep (Winbush, Gross, \& Kreitzer, 2007). Despite several methodological issues in these studies, overall, it appears to be increased trait mindfulness that most predicts improved sleep (Howell, Digdon, \& Buro, 2010). Furthermore, given that poor sleep predisposes individuals to poor mental and physical health, improved sleep quality might at least partially mediate the relationship between increased mindfulness and improved well-being (Howell, Digdon, Buro, \& Sheptycki, 2008). Given the increased prevalence of sleep issues in tertiary students (Lund, Reider, Whiting, \& Prichard, 2010), these findings add support for including mindfulness training in higher education.

Participants in both programmes reported improved listening when communicating with others. Reported implications for participants in dealings with patients included a more holistic understanding of the patient. Training healthcare workers in mindful communication has been shown to lead to improved empathy (Krasner et al., 2009) and better patient care (Beckman et al., 2012) as well as improved personal well-being and reduced burnout (Goodman \& Schorling, 2012). Although the MMov programme did not explicitly teach mindful communication, the facilitator intentionally modelled mindful communication in the group sessions in both programmes, which may explain the improvement reported by the participants. Alternatively, it is possible that increased trait mindfulness resulting from the MMov training may have intrinsically led to more mindful communication.

Participants also reported improved study engagement and greater productivity. Participants in both the MSR and MMov programmes reported reduced distractedness due to greater awareness of when they were distracted and being able to reengage attention more easily. Consequently, participants also reported increased concentration and increased study efficiency. Previous research has found that mindfulness may reduce distractedness and "default mode" activity (Brewer et al., 2011), and improve concentration (Lazar, 2005). These factors are likely to lead to better academic performance (Zenner, HerrnlebenKurz, \& Walach, 2014).

Although research shows that mindfulness leads to increased work engagement (Malinowski \& Lim, 2015), there is a paucity of literature on mindfulness and study engagement, with research focusing more on the effects of mindfulness on 
cognitive performance and academic achievement. Given the findings of the present study that mindfulness appears to boost study engagement, this area warrants further investigation. It is possible that mindfulness enhances work/study engagement during work/study times, but also the ability to volitionally shift attention fully to other activities that are not work or study related once the task is complete. From our data, it may be that mindfulness facilitates healthy work and study engagement by promoting attention switching, metacognition and focus.

Participants in the MMov group reported an increased awareness of body posture and movement. Increased awareness of their own movement appeared to lead to a greater appreciation of movement in others. This resulted in strategies to teach others new, corrective ways to move, therefore improving treatment efficacy. Participants reported being able to organise themselves more effectively and sustainably when working with each other and with simulated patients in practical classes. These findings suggest that mindful movement offers a unique dimension of benefit which may be well suited to and useful for physiotherapy students.

The present research had several limitations. It would be interesting for future researchers to combine qualitative interviews with validated self-report scales, stress biomarkers, academic performance and observer-rated scales of outcome variables such as patient care.

Students in this study self-selected by volunteering to participate. It is unknown whether the programme would have been as successful or well-received by a whole cohort of physiotherapy students who did not self-select. Future research should seek to deliver such programmes to entire cohorts in order to address this. Research conducted in students in similar university settings who receive mindfulness training as part of their core curriculum has shown that once students understand the rationale and background science, $90.5 \%$ report personally engaging with meditation and/or other applications of mindfulness (Hassed et al., 2009). It is likely to be similar in physiotherapy students, and this is something that future researchers should explore. The present study randomised participants into the MSR and MMov programmes. Both the meditation-based and movement-based interventions used in this study included common elements, such as an explicit stress reduction focus and an emphasis on informal mindfulness practice as well as meditation/movement practices. It might be advisable for future researchers to design interventions comparing only meditation and movement practices without these other elements. This would allow for a clearer understanding of the relative contribution of sitting meditation and mindful movement practices to various outcomes of interest.

Finally, it would have been interesting to include a control group who did not receive mindfulness training and was given some other active (non-mindfulness) intervention to account for the possible effects of simply participating in a programme or increasing social connectedness.

Notwithstanding these limitations, this was the first study we are aware of that investigates via qualitative interviews the acceptability of and benefits resulting from a mindfulness intervention based on sitting meditation and mindful movement designed specifically for physiotherapy students.

\section{CONCLUSION}

Overall, the students appeared to engage well with both forms of mindfulness training and reported a range of benefits to their well-being, study engagement, communication and clinical effectiveness as trainee physiotherapists. The MMov programme appeared to have an additional benefit, given its alignment with participants' existing interests as physiotherapists and the application of the increased movement awareness in client management. Given this, there is a case for including such mindfulness training in physiotherapy (and allied health) training programmes. Designing interventions that meet the specific needs of different cohorts may enhance engagement and is a recommendation of some researchers (e.g. Spinelli et al., 2019).

These findings provide a rationale for including mindfulness in physiotherapy courses, with the ready availability of online apps providing ongoing support of mindfulness practice. Further studies are required to replicate and extend these initial findings.

\section{KEY POINTS}

1. Both the meditation-based and movement-based interventions were acceptable to physiotherapy students with the mindful movement programme providing additional benefit as students applied their experiential awareness of movement into their practice as trainee physiotherapists.

2. Increased mindfulness led to healthier choices including improved diet, regular exercise and improved sleep which may have partially mediated improved well-being.

3. Participants reported improved listening and communication, which have been linked to improved empathy, better patient care and reduced practitioner burnout.

4. Participants reported awareness of the stress response, improved attention switching, metacognition and focus, and improve overall study engagement.

\section{DISCLOSURES}

No funding was obtained for this study. There are no conflicts of interest which may be perceived to interfere with or bias this study.

\section{PERMISSIONS}

Ethical approval was obtained from the Human Resources Ethics Committee of La Trobe University (FHEC1413). All participants gave written informed consent.

\section{ACKNOWLEDGEMENTS}

We thank Gemma Edwards for her assistance with conducting the interviews.

\section{ADDRESS FOR CORRESPONDENCE}

Janet McConville, Discipline of Physiotherapy, School of Allied Health, LaTrobe University, Victoria, Australia, 3086. Telephone: +61 3 94795855. Email: j.mcconville@latrobe.edu.au 


\section{REFERENCES}

Beckman, H. B., Wendland, M., Mooney, C., Krasner, M. S., Quill, T. E., Suchman, A. L., \& Epstein, R. M. (2012). The impact of a program in mindful communication on primary care physicians. Academic Medicine, 87(6), 815-819. https://doi.org/10.1097/ACM.0b013e318253d3b2

Black, D. S., O'Reilly, G. A., Olmstead, R., Breen, E. C., \& Irwin, M. R. (2015). Mindfulness meditation and improvement in sleep quality and daytime impairment among older adults with sleep disturbances: A randomized clinical trial. JAMA Internal Medicine, 175(4), 494-501. https://doi. org/10.1001/jamainternmed.2014.8081

Bond, A. R., Mason, H. F., Lemaster, C. M., Shaw, S. E., Mullin, C. S., Holick E. A., \& Saper, R. B. (2013). Embodied health: The effects of a mind-body course for medical students. Medical Education Online, 18, 20699. https:// doi.org/10.3402/meo.v18i0.20699

Braun, V., \& Clarke, V. (2006). Using thematic analysis in psychology. Qualitative Research in Psychology, 3(2), 77-101. https://doi. org/10.1191/1478088706qp063oa

Brewer, J. A., Worhunsky, P. D., Gray, J. R., Tang, Y.-Y., Weber, J., \& Kober, $H$. (2011). Meditation experience is associated with differences in default mode network activity and connectivity. Proceedings of the National Academy of Sciences, 108(50), 20254-20259. https://doi.org/10.1073/ pnas. 1112029108

Caldwell, K., Harrison, M., Adams, M., Quin, R. H., \& Greeson, J. (2010). Developing mindfulness in college students through movement-based courses: Effects on self-regulatory self-efficacy, mood, stress, and sleep quality. Journal of American College Health, 58(5), 433-442. https://doi. org/10.1080/07448480903540481

Chrisman, J. A., Christopher, J. C., \& Lichtenstein, S. J. (2009). Qigong as a mindfulness practice for counseling students: A qualitative study. Journal of Humanistic Psychology, 49(2), 236-257. https://doi. org/10.1177/0022167808327750

Dobkin, P. L., \& Hassed, C. S. (2016). Programme delivery. In P. L. Dobkin \& C. S. Hassed (Eds.), Mindful medical practitioners: A guide for clinicians and educators (pp. 75-87). Springer. https://doi.org/10.1007/978-3-31931066-4

Dyrbye, L. N., Thomas, M. R., \& Shanafelt, T. D. (2006). Systematic review of depression, anxiety, and other indicators of psychological distress among U.S. and Canadian medical students. Academic Medicine, 81(4), 354-373. https://doi.org/10.1097/00001888-200604000-00009

Epstein, R. M., Siegel, D. J., \& Silberman, J. (2008). Self-monitoring in clinical practice: A challenge for medical educators. Journal of Continuing Education in the Health Professions, 28(1), 5-13. https://doi.org/10.1002/ chp. 149

Fahrenkopf, A. M., Sectish, T. C., Barger, L. K., Sharek, P. J., Lewin, D., Chiang, V. W., ... Landrigan, C. P. (2008). Rates of medication errors among depressed and burnt out residents: Prospective cohort study. BMJ, 336(7642), 488 491. https://doi.org/10.1136/bmj.39469.763218.BE

Goodman, M. J., \& Schorling, J. B. (2012). A mindfulness course decreases burnout and improves well-being among healthcare providers. International Journal of Psychiatry in Medicine, 43(2), 119-128. https:// doi.org/10.2190/PM.43.2.b

Grossman, P., Niemann, L., Schmidt, S., \& Walach, H. (2004). Mindfulnessbased stress reduction and health benefits: A meta-analysis. Journal of Psychosomatic Research, 57(1), 35-43. https://doi.org/10.1016/s00223999(03)00573-7

Hassed, C., de Lisle, S., Sullivan, G., \& Pier, C. (2009). Enhancing the health of medical students: Outcomes of an integrated mindfulness and lifestyle program. Advances in Health Sciences Education, 14(3), 387-398. https:// doi.org/10.1007/s10459-008-9125-3

Hopkins, A., \& Proeve, M. (2013). Teaching mindfulness-based cognitive therapy to trainee psychologists: Qualitative and quantitative effects. Counselling Psychology Quarterly, 26(2), 115-130. https://doi.org/10.1080 /09515070.2013.792998
Howell, A. J., Digdon, N. L., \& Buro, K. (2010). Mindfulness predicts sleep-related self-regulation and well-being. Personality and Individual Differences, 48(4), 419-424. https://doi.org/10.1016/j.paid.2009.11.009

Howell, A. J., Digdon, N. L., Buro, K., \& Sheptycki, A. R. (2008). Relations among mindfulness, well-being, and sleep. Personality and Individual Differences, 45(8), 773-777. https://doi.org/10.1016/j.paid.2008.08.005

Kabat-Zinn, J. (2003). Mindfulness-based interventions in context: Past, present, and future. Clinical Psychology: Science and Practice, 10(2), 144156. https://doi.org/10.1093/clipsy/bpg016

Khoury, N. M., Lutz, J., \& Schuman-Olivier, Z. (2018). Interoception in psychiatric disorders: A review of randomised controlled trials with interoception-based interventions. Harvard Review of Psychiatry, 26(5), 250-263. https://doi.org/10.1097/HRP.0000000000000170

Kinser, P., Braun, S., Deeb, G., Carrico, C., \& Dow, A. (2016). "Awareness is the first step": An interprofessional course on mindfulness \& mindfulmovement for healthcare professionals and students. Complementary Therapies in Clinical Practice, 25, 18-25. https://doi.org//10.1016/j. ctcp.2016.08.003

Kolt, G. S., \& McConville, J. C. (2000). The effects of a Feldenkrais® Awareness Through Movement program on state anxiety. Journal of Bodywork and Movement Therapies, 4(3), 216-220. https://doi. org/10.1054/jbmt.2000.0179

Krasner, M. S., Epstein, R. M., Beckman, H., Suchman, A. L., Chapman, B., Mooney, C. J., \& Quill, T. E. (2009). Association of an educational program in mindful communication with burnout, empathy, and attitudes among primary care physicians. JAMA, 302(12), 1284-1293. https://doi. org/10.1001/jama.2009.1384

Larcombe, W., Finch, S., \& Sore, R. (2015). Who's distressed? Not only law students: Psychological distress levels in university students across diverse fields of study. Sydney Law Review, 37(243), 243-272.

Lazar, S. W. (2005). Mindfulness research. In C. K. Germer, R. D. Siegel, \& P. R. Fulton (Eds.), Mindfulness and psychotherapy (pp. 220-238). Guilford Press

Lo, K., Francis-Cracknell, A., \& Hassed, C. (2017). A Health Enhancement Programme for physiotherapy students: A mixed methods pilot study. New Zealand Journal of Physiotherapy, 45(3), 143-153. https://doi. org/10.15619/NZJP/45.3.06

Lund, H. G., Reider, B. D., Whiting, A. B., \& Prichard, J. R. (2010). Sleep patterns and predictors of disturbed sleep in a large population of college students. Journal of Adolescent Health, 46(2), 124-132. https://doi. org/10.1016/j.jadohealth.2009.06.016

Malinowski, P., \& Lim, H. J. (2015). Mindfulness at work: Positive affect, hope, and optimism mediate the relationship between dispositional mindfulness, work engagement, and well-being. Mindfulness, 6(6), 12501262. https://doi.org/10.1007/s12671-015-0388-5

McConville, J., McAleer, R., \& Hahne, A. (2017). Mindfulness training for health profession students - the effect of mindfulness training on psychological well-being, learning and clinical performance of health professional students: A systematic review of randomized and non-randomized controlled trials. Explore, 13(1), 26-45. https://doi. org/10.1016/j.explore.2016.10.002

McEwen, B. S. (2004). Protection and damage from acute and chronic stress: Allostasis and allostatic overload and relevance to the pathophysiology of psychiatric disorders. Annals of the New York Academy of Sciences, 1032(1), 1-7. https://doi.org/10.1196/annals.1314.001

Michalak, J., Burg, J., \& Heidenreich, T. (2012). Don't forget your body: Mindfulness, embodiment, and the treatment of depression. Mindfulness, 3(3), 190-199. https://doi.org/10.1007/s12671-012-0107-4

Payne, P., \& Crane-Godreau, M. A. (2015). Meditative movement for depression and anxiety. In F. B. Schuch, N. Rocha, \& E. L. Cadore (Eds.), Progress in physical activity and exercise and affective and anxiety disorders: Translational studies, perspectives and future directions (pp. 50-64). Frontiers Media SA. https://doi.org/10.3389/978-2-88919-471-1 
Price, C.J., \& Hooven, C. (2018). Interoceptive awareness skills for emotion regulation: Theory and approach of mindful awareness in body-orientated therapy (MABT). Frontiers in Psychology, 9, 798. https://doi.org/10.3389/ fpsyg.2018.00798

Price, C.J., Merrill, J.O., McCarty, R. L., Pike, K.C., \& Tsui, J.I. (2019) A pilot study of mindful body awareness training as an adjunct to office-based medication treatment of opioid use disorder. Journal of Substance Abuse Treatment. May 23 https://doi.org/10.1016/j.jsat.2019.05.013 [Epub ahead of print]

Segal, Z. V., Williams, J. M. G., \& Teasdale, J. D. (2002). Mindfulness-based cognitive therapy for depression: A new approach to preventing relapse. Guilford Press.

Shapiro, S.L., Carlson, L.E., Astin, J.A. \& Freedman, N. (2006). Mechanisms of mindfulness. Journal of Clinical Psychology, 62(3), 373-386. https://doi. org/10.1002/jclp.20237

Slonim, J., Kienhuis, M., Di Benedetto, M., \& Reece, J. (2015). The relationships among self-care, dispositional mindfulness, and psychological distress in medical students. Medical Education Online, 20(1), 27924 https://doi.org/10.3402/meo.v20.27924
Spinelli, C., Wisener, M., Khoury, B. (2019). Mindfulness training for healthcare professionals and trainees: A meta-analysis of randomised controlled trials. Journal of Psychosomatic Research, 120, 29-38. https:// doi.org/10.1016/j.jpsychores.2019.03.003

Stew, G. (2011). Mindfulness training for occupational therapy students British Journal of Occupational Therapy, 74(6), 269-276. https://doi.org/10 4276/030802211X13074383957869

van der Riet, P., Rossiter, R., Kirby, D., Dluzewska, T., \& Harmon, C. (2015) Piloting a stress management and mindfulness program for undergraduate nursing students: Student feedback and lessons learned. Nurse Education Today, 35(1), 44-49. https://doi.org/10.1016/j.nedt.2014.05.003

Winbush, N. Y., Gross, C. R., \& Kreitzer, M. J. (2007). The effects of mindfulness-based stress reduction on sleep disturbance: $A$ systematic review. Explore, 3(6), 585-591. https://doi.org/10.1016/j. explore.2007.08.003

Zenner, C., Herrnleben-Kurz, S., \& Walach, H. (2014). Mindfulness-based interventions in schools - A systematic review and meta-analysis. Frontiers in Psychology, 5, 603. https://doi.org/10.3389/fpsyg.2014.00603 


\section{Post-intervention interview questions (week 6 and 7)}

Opening statement 1: You have now completed the six-week mindfulness programme.

Opening question 1: What is different for you since completing the programme? Example of sub-question: What is different in each aspect of your life from mindfulness?

Opening statement 2: We are interested in evaluations and your unique experiences of mindfulness.

Opening question 2: Describe your experience of the programme.

Opening statement 3: Initial mindfulness training often makes people more aware of the regular habits of their attention in meditation and/or daily life.

Opening question 3: Have you been more aware of "default mode" (times where you were not engaged in what you were doing)?

Opening statement 4: One of the things mindfulness aims to do is to make people more aware of their thoughts.

Opening question 4: Describe a recent situation where you have had greater awareness and/or less reactivity.

Opening statement 5: Another aspect of mindfulness is that people become more aware of their body.

Opening question 5: Describe a situation where you have become more mindful of your body recently.

Opening statement 6: Mindfulness can change the way people relate to themselves and how one identifies with aspects of themselves.

Opening question 6: Describe the ways your relationship with your thoughts, feelings and body sensations changed as you progressed through the course.

Opening statement 7: We are interested in the relevance of mindfulness to physiotherapy students.

Opening question 7: What are the ways you think learning mindfulness will help you in your work as a physiotherapist?

Opening statement 8: This brings us to the last question. Opening question 8: Is there anything else that you would like to add about your experience?

\section{Follow-up interview questions (week 12)}

Opening statement 1: Last time we discussed several experiences, thoughts and opinions relating to mindfulness. Opening question 1: What can you tell me about how you view mindfulness now? Example of sub-question: Can you please describe what the experience of a mindful moment is like for you?

Opening statement 2: I am interested in how people become more mindful.

Opening question 2: At any stage, has there been a process of becoming more mindful in your daily life that you can describe to me?

Opening statement 3: Research suggests our emotions can be embodied.

Opening question 3: Can you describe an instance where your emotions have manifested in your body?

Opening statement 4: Regardless of whether you have been practising mindfulness recently, I am interested in how all the mindfulness you have done may still be affecting you now. Opening question 4: Can you describe the benefits you currently feel from mindfulness?

Opening statement 5: I am interested in what has lasted from mindfulness.

Opening question 5 . What are the main things from the programme that have stayed with you?

Opening statement 6: I am interested in how mindfulness gets used at different times.

Opening question 6: Can you describe how mindfulness has influenced your studies over the semester?

Opening statement 7: Different things help or hinder people in starting and maintaining a regular practice of mindfulness. Opening questions 7: What things have supported you in building a mindfulness practice? What have been obstacles to mindfulness practice for you?

Opening statement 8: I am interested in the role of others in an individual's practice of mindfulness. You have now had about six weeks with weekly group support and about six weeks where you could have continued to practise individually. Opening Question 8: What was the effect of having the group and then not having the group?

Opening statement 9: Research shows that mindfulness is associated with changes in authentic functioning. Opening question 9: Do you feel more in touch with yourself?

Opening statement 10: Last time we spoke, you talked about which seemed prominent to you.

Opening question 10: How has that been going?

Individual follow-up: Are there any other experiences or benefits of mindfulness you see that you would like to share? Is there anything else that you would like to contribute to this research? 


\section{Appendix B}

\section{ADDITIONAL QUOTES FROM PARTICIPANTS}

\section{Mental Health}

"Maybe the biggest advantage of mindfulness is to be aware of myself. Knowing myself" (Participant 4).

"I have become a lot more aware of tension and where I carry tension, and the sort of things that trigger when I get tense" (Participant 7).

"I am quite hard on myself usually, especially with assignments coming back. If I am not happy with it, I tend to get angry at myself and very self-critical. Knowing now how to be gentler with myself and reminding myself about that, I have managed to not be so reactive" (Participant 7).

"I don't feel as overwhelmed with things with regards to uni. Things seem more achievable. I suppose just taking everything step by step" (Participant 7).

"Being aware of over-emotional or angry responses has helped to just let them be and I feel a bit calmer rather than up and down, and flight and fight" (Participant 5).

"My attitudes to my thoughts and my feelings are less judgmental and more accepting. They are there and they are what they are" (Participant 3).

"I've noticed when I'm being more reactive ... and I can sort of take a step back from it or I can at least make a decision whether I am going to continue to react or step away" (Participant 10).

"In relationships with family and friends, how I feel towards others, the sort of emotions that sometimes come up with different people, I have noticed a lot more. If I feel negative towards someone, I can pick that up, and I realise that's me, that's my feelings, that's not them that is causing anything, that's my attitude towards people. This motivates me to have a more positive attitude towards people. I can change that and often that changes the way I interact with them, and maybe it's not such a negative experience with them after all" (Participant 7).

\section{Self-care}

"Dancing, just moving in a way that my body wanted to, helped me forget about stressors and other things that are distracting" (Participant 3).

"Enjoyed most the feeling of being kind of present during my everyday tasks, so even walking from class to class, class to lunch, going home and going to work I would find myself tuning back into what I was actually doing, and I really enjoyed slowing down to eat" (Participant 11).

"I like to exercise, and I am a ballet dancer. I am now more able to focus on them rather than just being there and not actually mentally being there. While I know they are my hobbies, they used to stress me out as I would be thinking about what (I perceived) I was supposed to be doing rather than my hobbies. Now they are more enjoyable" (Participant 2).

\section{Communication}

"I have got a wife and two kids. I am now more aware of trying to divide my attention between two things, and it is not really working. So, if my kids need attention, I am now more likely to stop whatever else I was doing and give them all the attention and then when that's done, go back to whatever and give all my attention to that, rather than trying to do two things at once" (Participant 5).

\section{Study engagement}

"I find that I spend less time kind of zoning out, just looking at the screen, [and am] less tempted to come and go and look at YouTube or Facebook during my study" (Participant 11).

"Definitely more assured, or more willing to be wrong ... now I am a bit happier to be a bit more assertive and ask questions" (Participant 6).

“When I'm studying, and catch [myself] procrastinate [sic] a bit, usually I get angry, now I'm just, 'It's ok, it happens', and bring myself back and refocus" (Participant 7).

\section{Movement awareness}

"Experiencing mindful movement allows you to see different ways to help your patient, like understanding how each of the body's parts are all connected together" (Participant 3).

"I've been feeling my posture a lot more and able to correct it." (Participant 9).

"Hands-on practical work, I can actually feel what's going on, not just doing it" (Participant 2).

\section{Negative experiences and challenges}

"I still view it as being very critical. Having said that, I am not practicing it as much as I was then [during the intervention], too many other things at the forefront of my mind" (Participant 6). 